\title{
Recovery pumping system handling water hyacinth: volume reduction criteria
}

\author{
Mohamed F. Khalii ${ }^{1}$, Sadek Z. Kassab ${ }^{2 *}$, Ahmed A. Abdel Naby ${ }^{3}$, and Ali Azouz ${ }^{4 *}$ \\ 1, 2, 3 Mechanical Engineering Department Faculty of Engineering, Alexandria University \\ Alexandria, 21544, Egypt \\ ${ }^{4}$ The Petroleum Projects and Technical Consultation Co (PETROJET), Egypt. \\ *Present Adress: Mech. Eng. Dept., College of Engineering and Technology, Arab Academy \\ for Science and Technology and Maritime Transport, Alexandria, Egypt \\ ${ }^{*}$ Corresponding author: azouz19680409@yahoo.com
}

\begin{abstract}
To obtain maximum benefits from water hyacinth recovery pumping system, a system should be designed to achieve maximum quantity from water hyacinth as well as maximum volume reduction to facilitate transportation, the process which cost a lot of money. The present experimental study deals with the effect of varying cutter blade number, $\beta$ and cutter speed to determine the changes in the water hyacinth recovery volume. Experimental results are presented for the percent reduction in Nile water hyacinth volume, $\Delta \mathrm{V} \%$. Within the operating range of the considered parameters, the obtained results show that the reduction in Nile water hyacinth volume, $\Delta \mathrm{V} \%$, increases with the increase of cutter blade number, $\beta$. The effect of varying cutter speed ratio, $\mathrm{N} / \mathrm{N}_{\max }$, depends on the operating range of the speed ratio. The prototype water hyacinth recovery pumping system reduced the recovery water hyacinth volume up to $71.2 \%$, at cutter blade number, $\beta=5$ and cutter speed, $\mathrm{N}_{\max }=2800 \mathrm{rpm}$.
\end{abstract}

Keywords: Water hyacinth -Centrifugal pump - Volume reduction

\section{INTRODUCTION}

Environmental engineers in developing countries have a special responsibility for development of simple and economical methods of water treatment, disposal and pollution control, which can ensure a healthy environment at affordable costs. For this point, the problem of handling water hyacinth appears in the picture. Water hyacinth is considered to be the most prolific plant on the earth. Scientists and technologists have been making efforts for its extermination as its growth in rivers and lakes. This tropical plant can cause infestations over large areas of water resources and consequently lead to series of problems, (Malik, 2007 and Choudhary, 2002). Attempts have been geared towards the use a suitable methods for preventing the spread of, or eradication of, water hyacinth. On the other hand, much attention has been focused on the utilization of water hyacinth for a variety of applications (Gunnarsson and Petersen, 2007).

Using the water hyacinth as a substrate for the production of biogas is an advantageous control strategy because it permits a "productive fight" against the plant's invasion. The stock, which is available in a given space and time, is renewable, and all of the harvested plants are replenished within a growing season, (Almoustapha et al. 2009).

The range of social, economic and environmental problems caused by water hyacinth is generally well perceived. However, quantitative data are not usually available to give an idea of the real implications and impacts on the communities. This presents a challenge to socio-economists to quantify impacts and thus define the real problems caused by water hyacinth.

The water hyacinth transportation problem comes to be of the top concern. By overcome the problem of transportation and saves money, utilization of water hyacinth or transport to its dumping places without healthy problem becomes a beneficial processes. Mathur and Singh (2004) developed a water hyacinth chopper with crusher to reduce volume and weight of freshly harvested water hyacinth to facilitate transportation. The prototype machine reduced the specific volume and weight of fresh water hyacinth up to $64 \%$ and $32 \%$ respectively. 
Khalil et al. (2009, 2010a, b and c) reviewed extensively the harm effects as well as the benefits of the water hyacinth and there is no need to repeat it here again. In addition, they studied experimentally the effect of varying the operating parameters on the performance of a recovery pumping system handling Nile water hyacinth. The operating parameters considered in Khalil et al. (2010a) were pump suction inclination angle, water height above pump inlet, inlet suction cone diameter, and pump flow rate. Meanwhile, Number of cutter blades, with/without scrapper, plant parts (complete plant, plant without roots and separate leaves) and water hyacinth concentration are the operating parameters considered in Khalil et al. (2009). They studied the variation of all these parameters on the Nile water hyacinth recovery rate. Moreover, Khalil et al. (2010c) introduced a parameter called the effectiveness to evaluate the performance of a recovery pumping system handling water hyacinth. The effectiveness is defined as the ratio between the rate of water hyacinth quantity collected and the mixture flowrate (water-water hyacinth).

Investigating the reduction in water hyacinth volume is the main interest of the present study. This interest appeared indirectly before in the previous studies by the present authors (Khalil et al. 2009, 2010a, b and c). In addition, the present experimental study deals with the effect of varying cutter blade number, $\beta$ and cutter speed, $\mathrm{N}$, to determine changes in recovery water hyacinth volume.

EXPERIMENTAL SET UP: Figure 1 shows the steps of the process of volume reduction of Nile water hyacinth starting from the collection area to the collecting tank in the experimental set up. In addition, a schematic diagram and a photo of the recovery pumping system used in the present study is shown in Fig. 2. Details of the experimental setup used in the present study and the operating procedure are given by Khalil et al. (2009). The cutter rotational speed was regulated through a variable frequency inverter type. A volume scalar is used to get the volume of recovered water hyacinth. Details of the centrifugal pump unit used in the experimental study, its specifications and performance curve and the specifications of the three cones used in the present study and connected to the pump suction pipe are given by Khalil et al. (2010a). Centrifugal pump impeller with double channel type was used. Scrapper system is also used.

In order to evaluate economically the benefits of using the water hyacinth recovery pumping system, a parameter called volume reduction, $\Delta \mathrm{V}$, is used in the present study.

The volume reduction, $\Delta \mathrm{V}$, is defined as:

$$
\Delta \mathrm{V}=\left[\left(\mathrm{V}_{1}-\mathrm{V}_{2}\right) / \mathrm{V}_{1}\right]
$$

Where: $V_{1}$ is the volume of water hyacinth before recover.

$$
V_{2} \text { is the volume of water hyacinth after }
$$
recovers.

This parameter reflects a major part of the cost reduction in the process of handling water hyacinth.

All experiments are carried at ambient temperature. The uncertainty of the water hyacinth volume, $\mathrm{V}$ is \pm $2.5 \%$ 
Am. J. Sci. Ind. Res., 2010, 1(3): 618-627

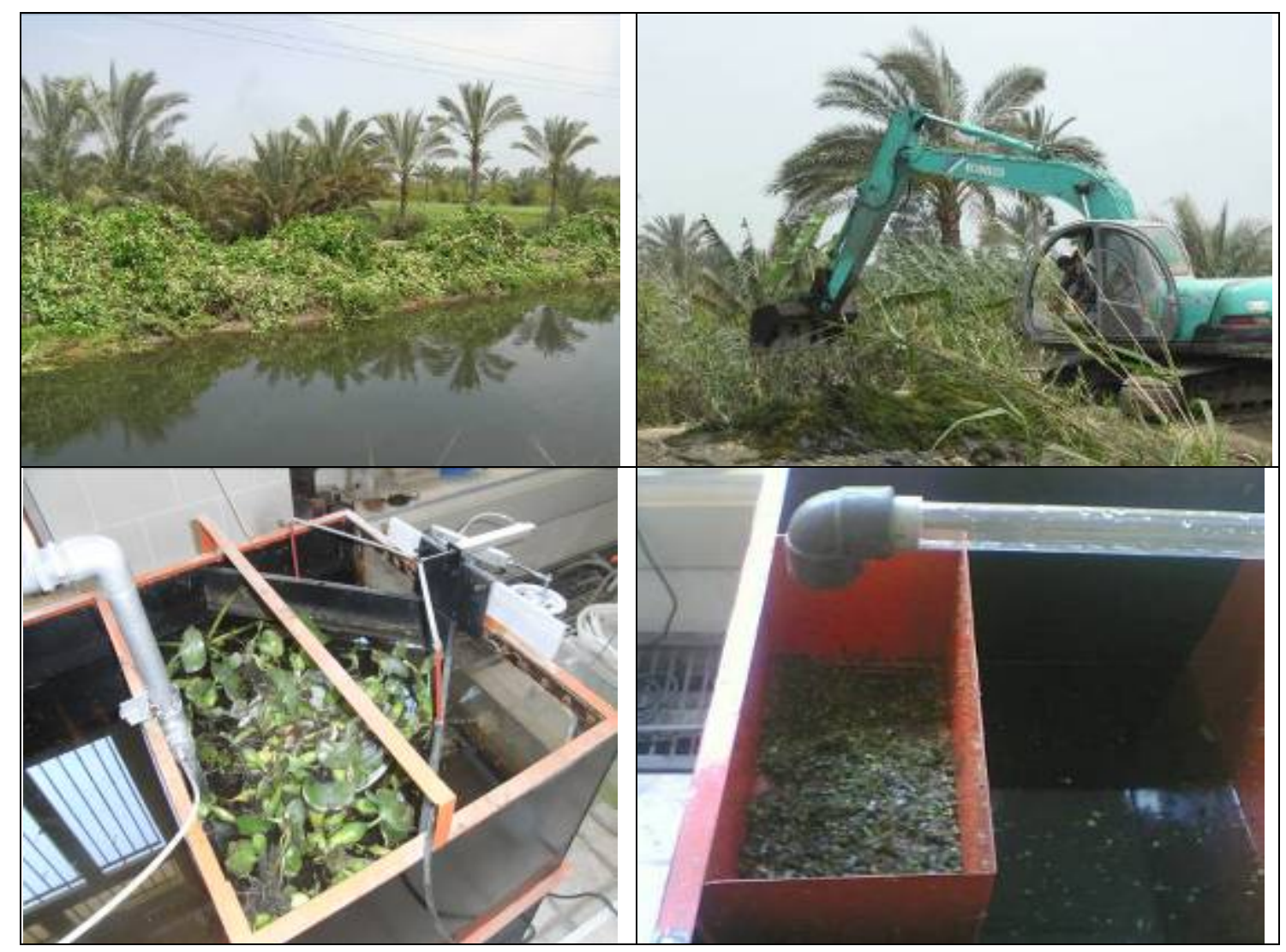

Fig. 1 Steps of the process of volume reduction
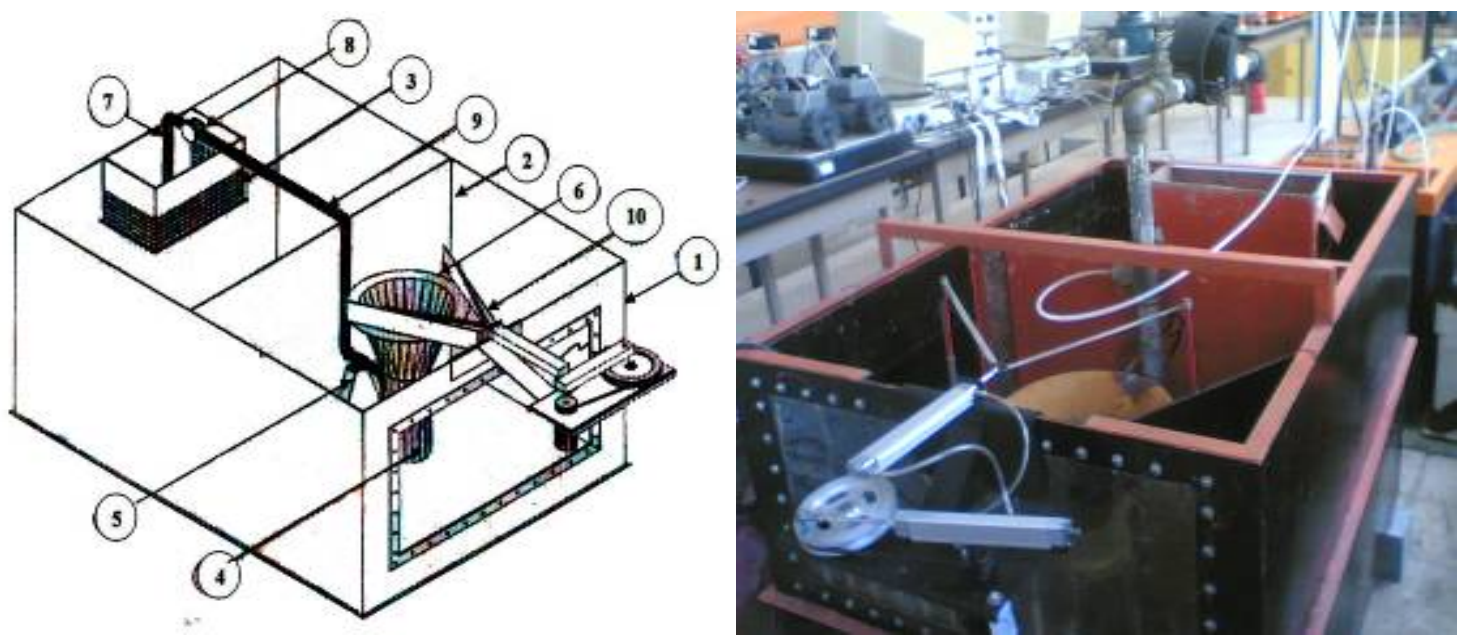

1. A steel tank 2. Buffer plate

5. Steel frame

10. scraper system
3.An auxiliary tank 4. Transfer pump

7. Perspex pipe
9. Pipe

Fig. 2 The experimental setup 


\section{RESULTS AND DISCUSSIONS}

Figures 3 to 6 show the variation of percentage reduction in water hyacinth volume, $\Delta \mathrm{V} \%$, with cutter blade number, $\beta$. It is clear that as the cutter blade number, $\beta$, increases, the percentage reduction in water hyacinth volume, $\Delta \mathrm{V} \%$, increases. This is due to the increase in cutter blade number, $\beta$, leads to cutting the water hyacinth to very small sizes and small thickness. In addition, the plant lost all containing water which also helps in squeeze the plant so the percentage volume reduction, $\Delta \mathrm{V} \%$, increases. Figure 3 shows that for certain value of cutter blade number, $\beta$, as the submergence ratio, $\mathrm{H} / \mathrm{D}_{\mathrm{S}}$ increases $\Delta \mathrm{V} \%$ increases until it reaches a certain maximum value before it falls down with the increase of the submergence ratio, $H / D_{S}$. The minimum and maximum reduction in water hyacinth volume, $\Delta \mathrm{V} \%$, was $44.8 \%$ at $\beta=1, \mathrm{H} / \mathrm{D}_{\mathrm{S}}=0.25$ and $70 \%$ at $\beta=5, H / D_{S}=0.5$ respectively.

Figure 4 shows that, for certain value of cutter blade number, $\beta$, as the inclination angle of the centerline of the pump suction cone with respect to the vertical plane, $\theta$, increases, the percentage reduction in water hyacinth volume, $\Delta \mathrm{V} \%$, decreases. This is in agreement of the previous results of Khalil et al. 2009, 2010a, b and c. The minimum and maximum reduction in Nile water hyacinth volume, $\Delta \mathrm{V}$, was $37.6 \%$ at $\beta=1, \theta=25^{\circ}$ and $70 \%$ at $\beta=5, \theta=0^{\circ}$ respectively.

Figure 5 shows that, for certain value of cutter blade number, $\beta$, as mixture volume flow rate ratio, $Q / Q_{\max }$, increases, the reduction in water hyacinth volume, $\Delta \mathrm{V} \%$, increases. The minimum and maximum reduction in water hyacinth volume, $\Delta \mathrm{V}$, was $30.4 \%$ at $\beta=1, Q / Q_{\max }=0.2$ and $70 \%$ at $\beta=5, Q / Q_{\max }=1$ respectively.

Figure 6 shows that, for certain value of cutter blade number, $\beta$, as cone diameter ratio, $D_{i} / D_{s}$, increases, the reduction in water hyacinth volume, $\Delta \mathrm{V} \%$, increases. These results demonstrate that the modification in the suction pumping system by using cone inlet, which leads to increase the inlet area to the pump, is helpful and strongly effect in reducing the water hyacinth volume. The minimum and maximum reduction in water hyacinth volume, $\Delta \mathrm{V} \%$, was $26.8 \%$ at $\beta=1, D_{i} / D_{s}=1$ and $70 \%$ at $\beta=5$, $D_{i} / D_{s}=4$ respectively.

Figures 7 to 10 show the variation of the percentage reduction in water hyacinth volume, $\Delta \mathrm{V} \%$, with cutter speed ratio, $\mathrm{N} / \mathrm{N}_{\max }$, In general, the reduction in water hyacinth volume, $\Delta \mathrm{V} \%$, increases as the cutter speed ratio, $\mathrm{N} / \mathrm{N}_{\max }$, increases until it reaches a maximum value after that it decreases. For small cutter speed, the ability of cutting water hyacinth is decreases because pumping system take time to complete the cutting process, so the sizes of water hyacinth become bigger than for the case of higher cutter speed. This ability increases as the cutter speed ratio, $\mathrm{N} / \mathrm{N}_{\max }$, increases until it reaches a maximum value. After that and at high $\mathrm{N} / \mathrm{N}_{\max }$, the amount of surface water hyacinth moved towards the cutters becomes less than the ability of the pumping system. Consequently, the reduction in water hyacinth volume, $\Delta \mathrm{V} \%$, decreases. In additional, this decrease in the ability of reducing the volume reduction ratio is due to the reduction of cutting time within the pump impeller due to the increase in cutter speed.

For certain value of cutter speed ratio, $N / N_{\max }$, the variation of the percentage reduction in water hyacinth volume, $\Delta \mathrm{V} \%$, with the variation all the other parameters, namely, submergence ratio, $H / D_{S}$, the inclination angle of the centerline of the pump suction cone with respect to the vertical plane, $\theta$, mixture volume flow rate ratio, $Q / Q_{\max }$, and cone diameter ratio, $D_{i} / D_{s}$, has the same trend as the corresponding cases for the cutter blade number, $\beta$, shown in Figs. 3 to 6 .

It is important to point out that, a look to Fig. 10 indicates that the case of $D_{i} / D_{s}=1$ is different from the other cases for $D_{i} / D_{s}>1$. In order to investigate this indication, more results filling the gap between $D_{i} / D_{s}=1$ and $D_{i} / D_{s}=3$ are presented in Fig. 11. This figure shows that for the case of cylinder pump inlet, $D_{i} / D_{s}=1$, as the cutter speed ratio, $N / N_{\max }$, increases the reduction in water hyacinth volume, $\Delta \mathrm{V} \%$, almost constant (there is a small change $(\Delta \mathrm{V} \%=38.8 \rightarrow 40$ $\%)$. In addition, for certain value of the cutter speed ratio, $\mathrm{N} / \mathrm{N}_{\max }$, as the inlet cone diameter increases the reduction in water hyacinth volume, $\Delta \mathrm{V} \%$, increases sharply. This can be related to the increase in inlet surface area. The increase in area helps in increasing the availability of water hyacinth in the effective suction zone. Meanwhile, for the cutter speed ratio, $\mathrm{N} / \mathrm{N}_{\max }=0.86,0.93$ and 1 the same trend as the case of $\mathrm{N} / \mathrm{N}_{\max }=0.79$ is obtained.

Figure 12 shows the variation of reduction in water hyacinth volume, $\Delta \mathrm{V} \%$, with the water hyacinth concentration ratio, $M / M_{\max }$. The results show that the reduction in water hyacinth volume, $\Delta \mathrm{V} \%$, increases as the concentration ratio of the floating water hyacinth ratio, $M / M_{\max }$, increases sharply until it reaches an almost constant value for all value of the concentration ratio, $\mathrm{M} / \mathrm{M}_{\max }$ 
Am. J. Sci. Ind. Res., 2010, 1(3): 618-627

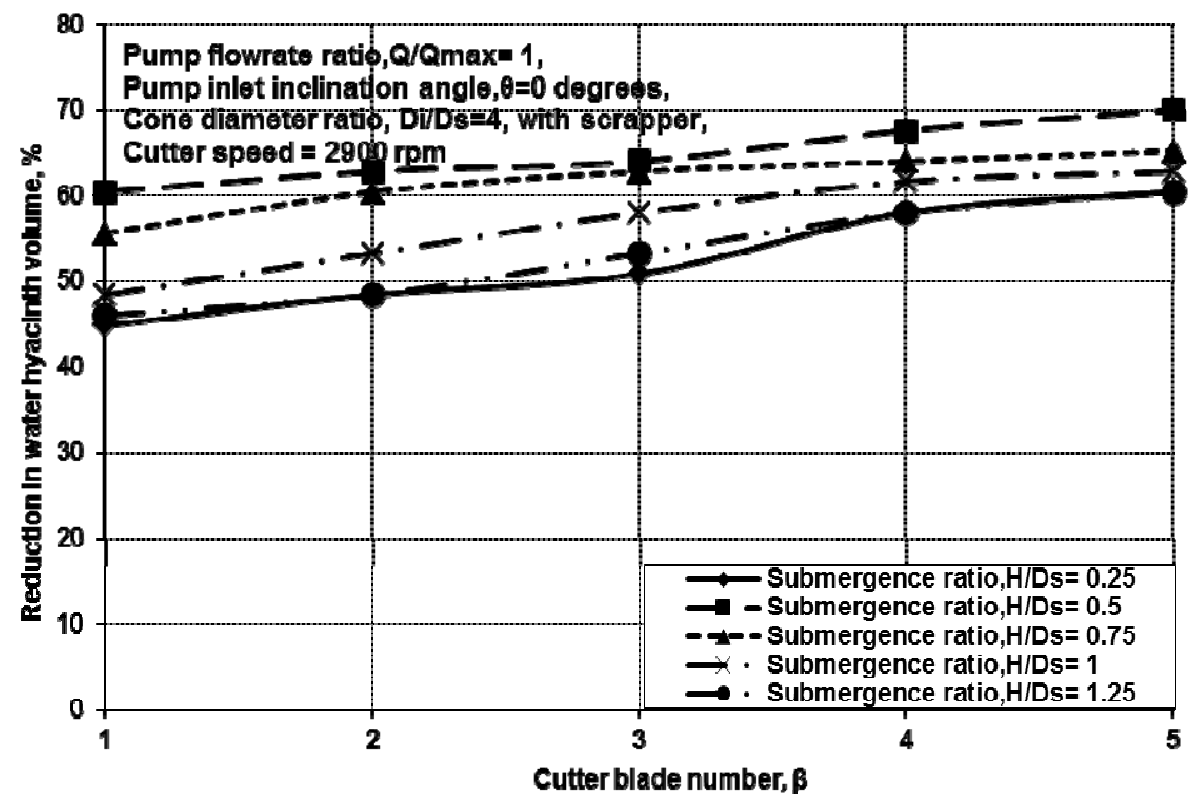

Fig 3 Variation of the percentage reduction in Nile water hyacinth volume, $\Delta V \%$, with the cutter blade number, $\beta$, at various values of submergence ratio, $H / D_{s}$.

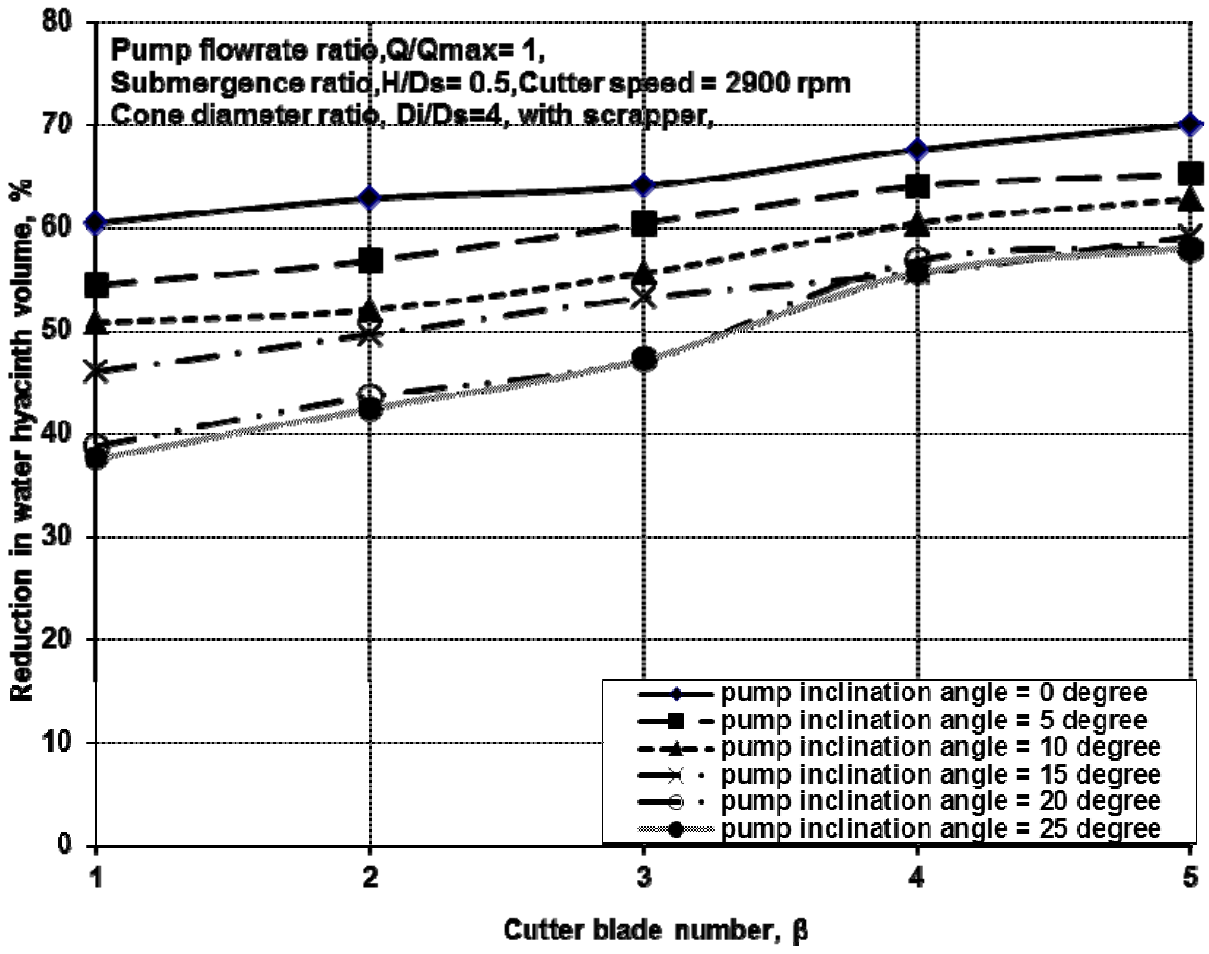

Fig 4 Variation of the percentage reduction in Nile water hyacinth volume, $\Delta V \%$, with the cutter blade number, $\beta$, at various values of pump inclination angle, $\theta$. 
Am. J. Sci. Ind. Res., 2010, 1(3): 618-627

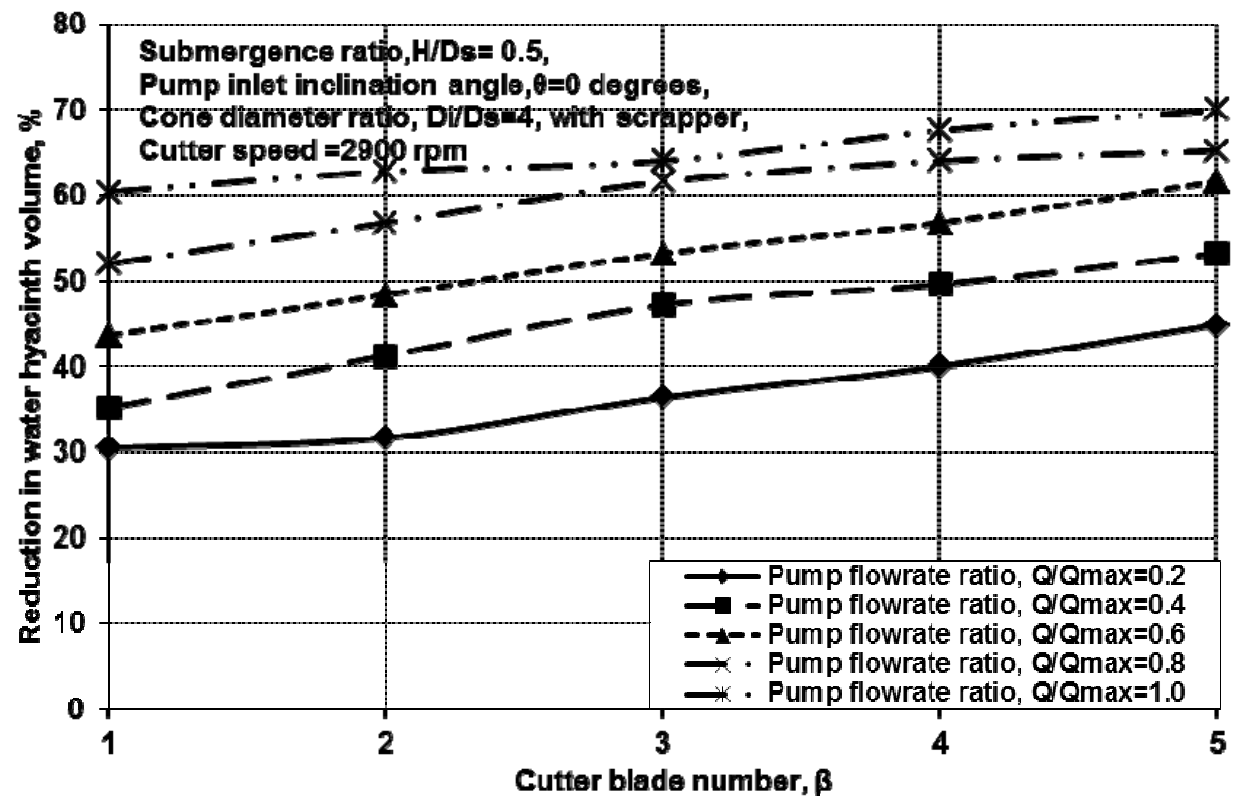

Fig 5 Variation of the percentage reduction in Nile water hyacinth volume, $\Delta V \%$, with the cutter blade number, $\beta$, at various values of flowrate ratio, $Q / Q_{\max }$.

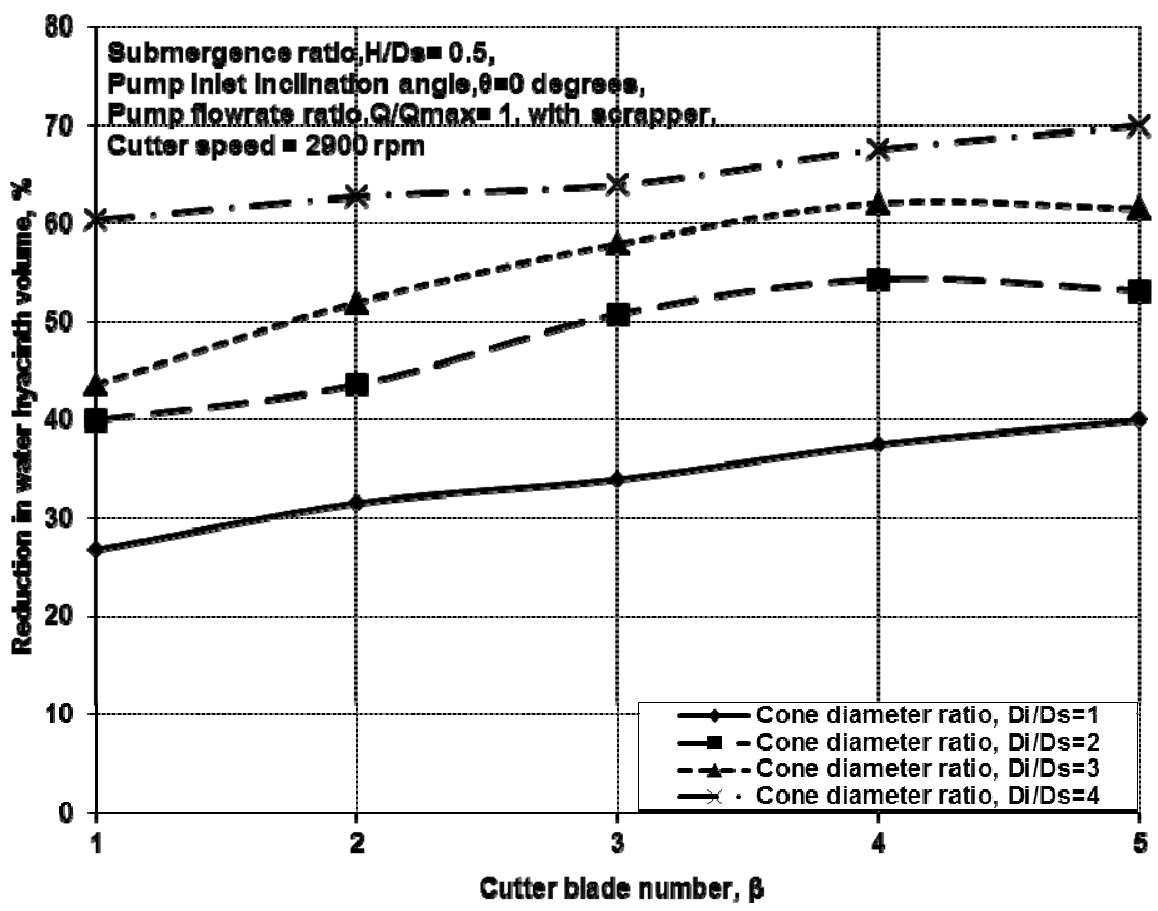

Fig 6 Variation of the percentage reduction in Nile water hyacinth volume, $\Delta \mathrm{V} \%$, with the cutter blade number, $\beta$, at various values of cone diameter ratio, $D_{i} / D_{s}$. 


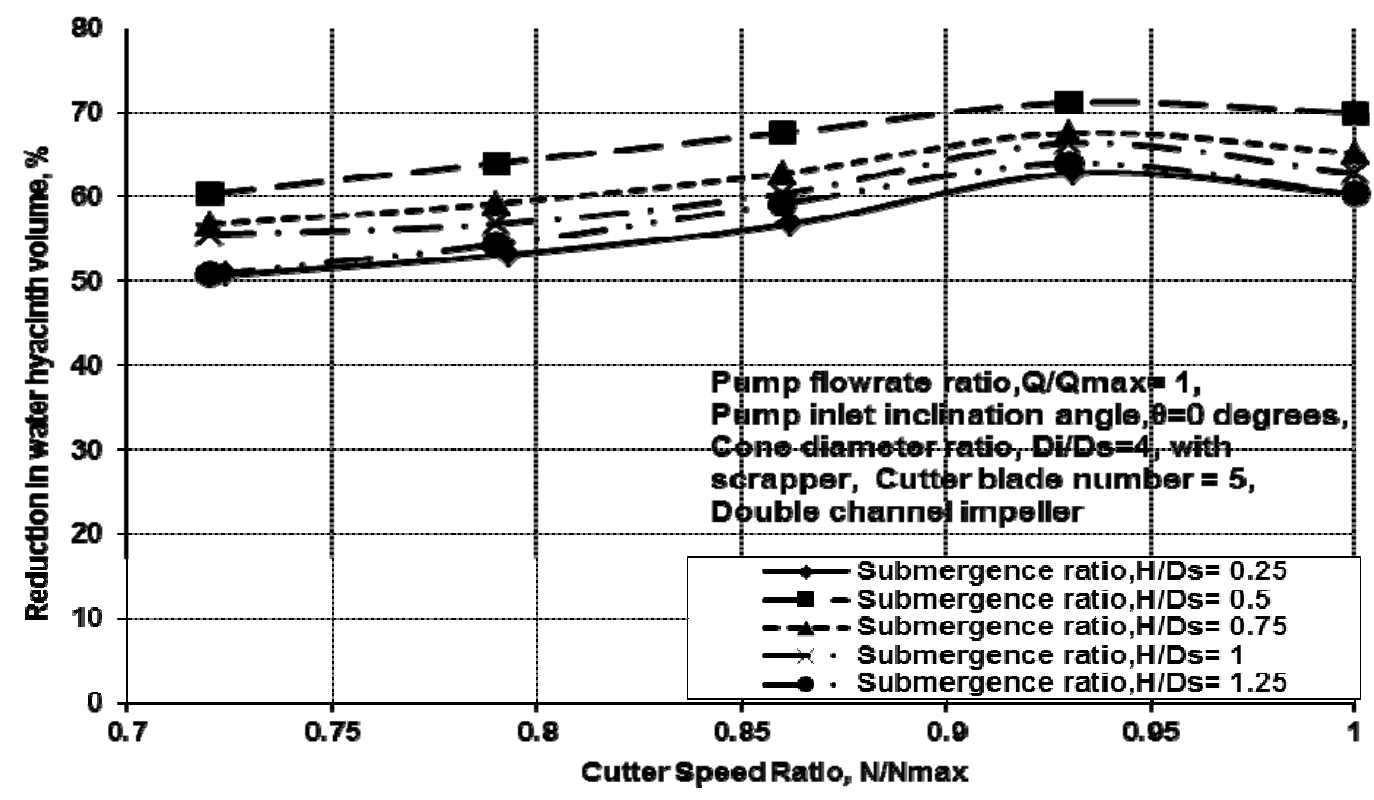

Fig 7 Variation of the percentage reduction in Nile water hyacinth volume, $\Delta \mathrm{V} \%$, with the cutter speed ratio, $\mathrm{N} / \mathrm{N}_{\text {max }}$, at various values of submergence ratio, $H / D_{s}$.

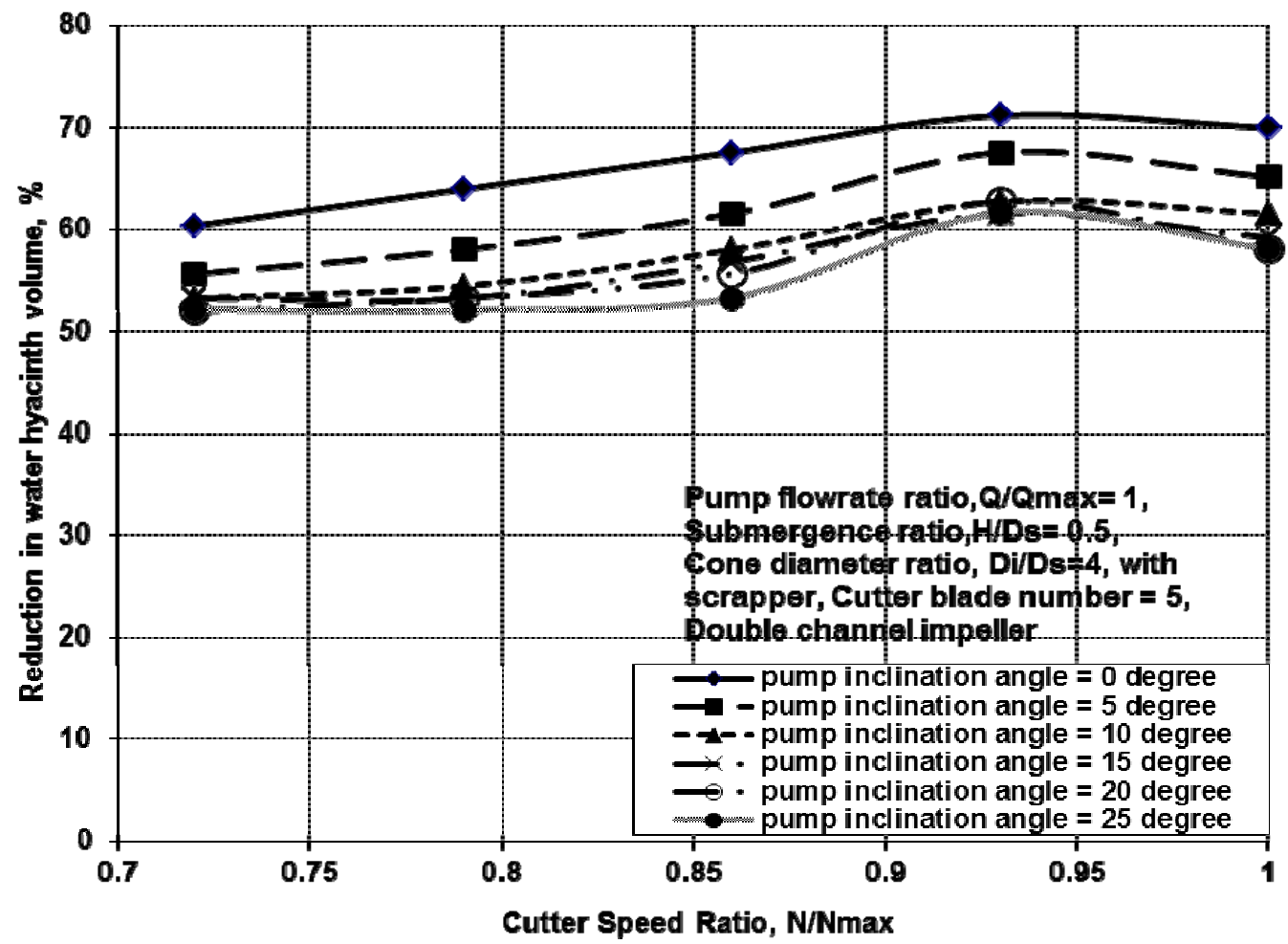

Fig 8 Variation of the percentage reduction in Nile water hyacinth volume, $\Delta \mathrm{V} \%$, with the cutter speed ratio, $\mathrm{N} / \mathrm{N}_{\text {max }}$, at various values of pump inclination angle, $\theta$. 
Am. J. Sci. Ind. Res., 2010, 1(3): 618-627

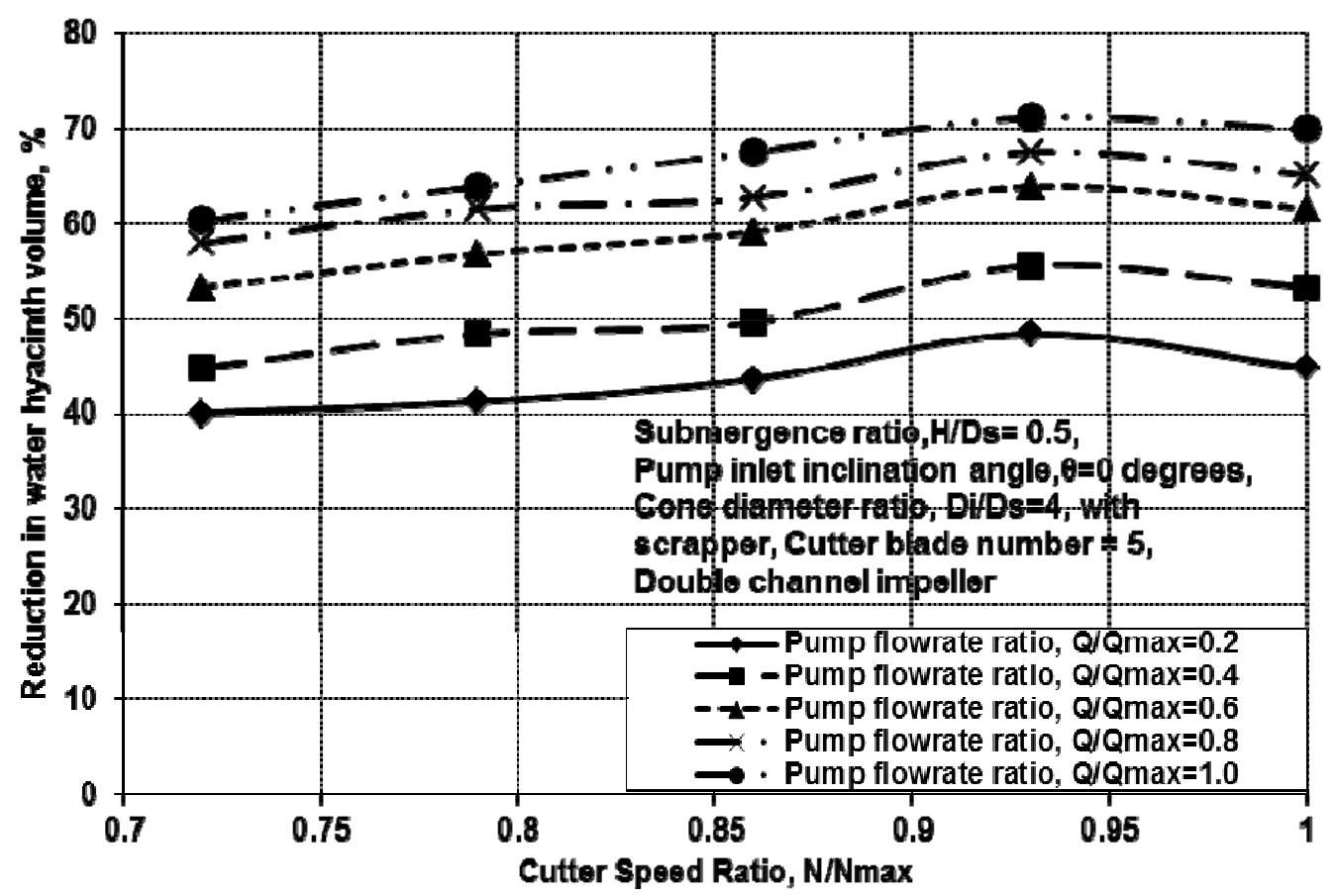

Fig 9 Variation of the percentage reduction in Nile water hyacinth volume, $\Delta V \%$, with the cutter speed ratio, $N / N_{\max }$, at various values of flowrate ratio, $Q / Q_{\max }$.

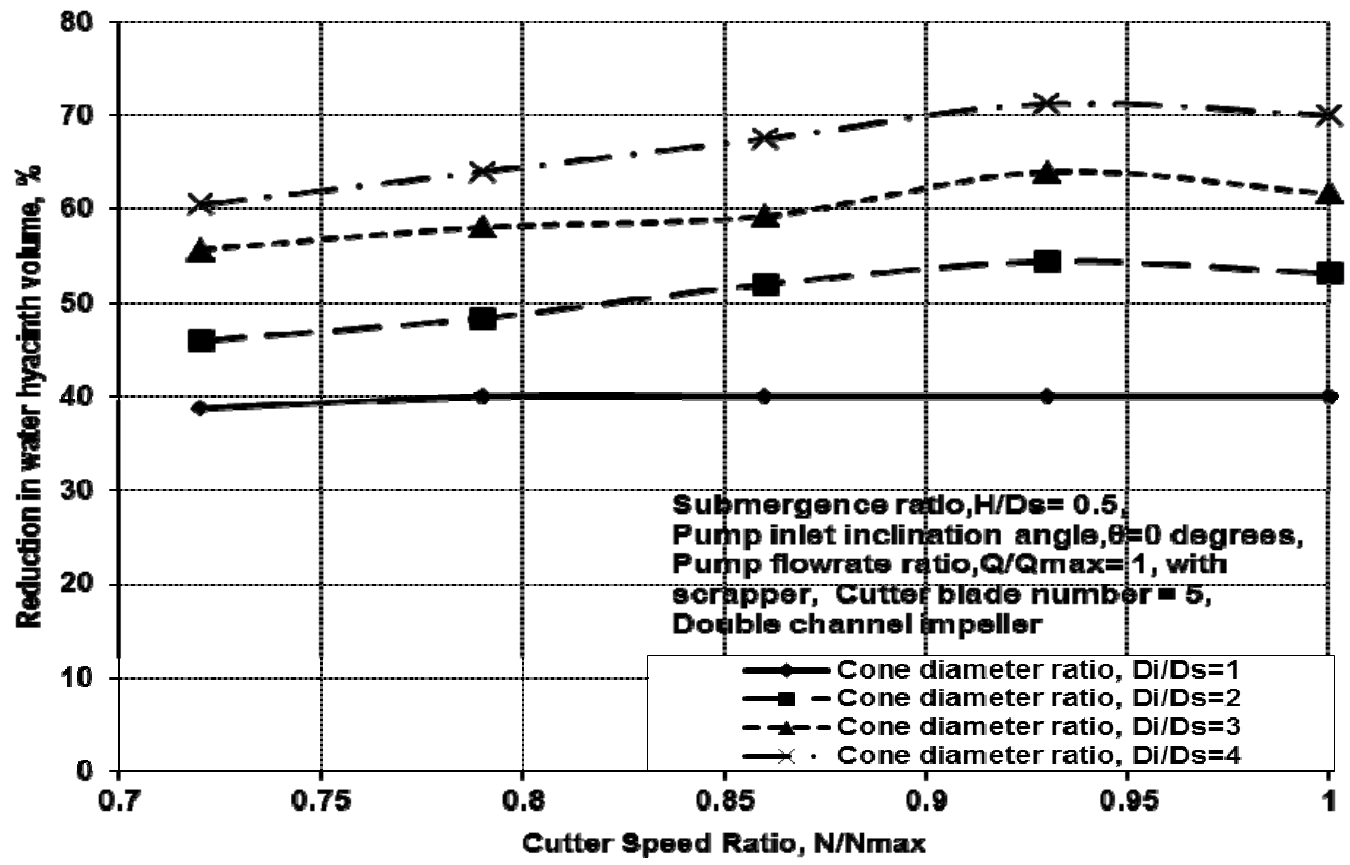

Fig 10 Variation of the percentage reduction in Nile water hyacinth volume, $\Delta V \%$, with the cutter speed ratio, $N / N_{\max }$, at various values of cone diameter ratio, $D_{i} / D_{s}$. 
Am. J. Sci. Ind. Res., 2010, 1(3): 618-627

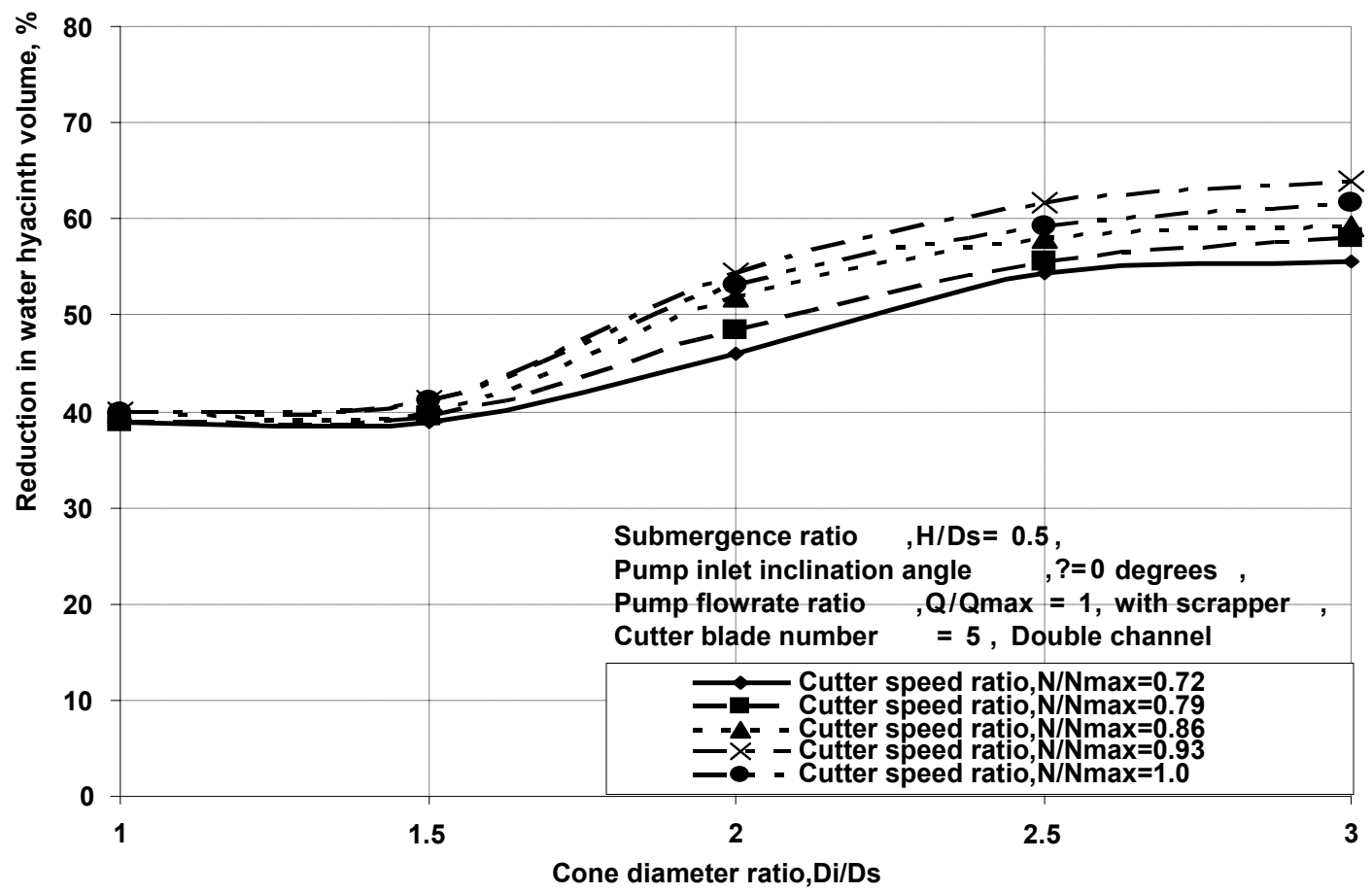

Fig 11 Variation of percentage reduction in Nile water hyacinth volume, $\Delta V \%$, with cone diameter ratio, $D_{i} / D_{s}$, at various cutter speed ratio, $\mathrm{N} / \mathrm{N}_{\max }$

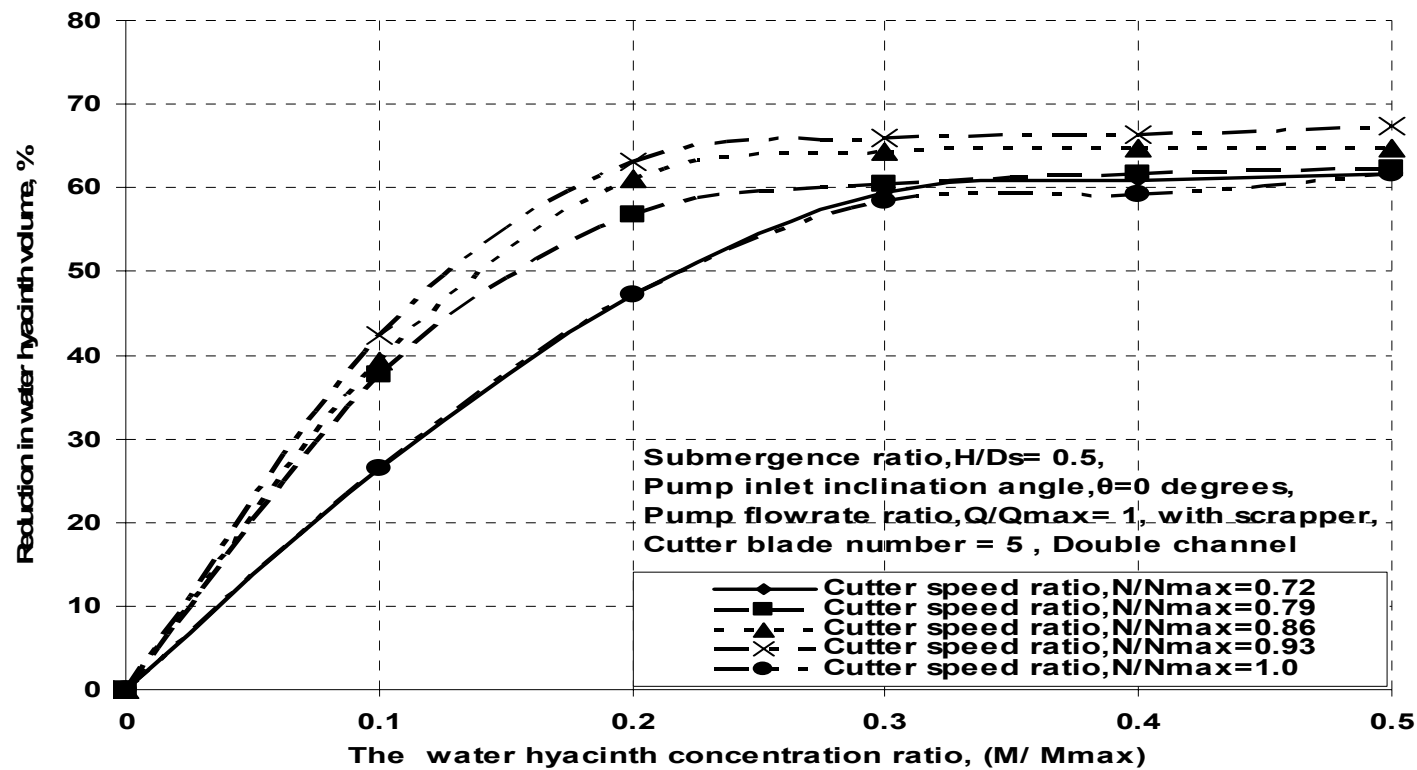

Fig 12 Variation of percentage reduction in Nile water hyacinth volume, $\Delta \mathrm{V} \%$, with the water hyacinth concentration ratio, $M / M_{\max }$ at various cutter speed ratio, $N / N_{\max }$ 
Am. J. Sci. Ind. Res., 2010, 1(3): 618-627

\section{CONCLUSIONS}

From the presented results and related discussions the following conclusions can be obtained:

1. As the cutter speed increases the reduction in water hyacinth volume, $\Delta \mathrm{V} \%$, increases until it reaches a certain maximum value before it falls down with the increase of cutter speed,

2. The reduction in water hyacinth volume, $\Delta \mathrm{V} \%$, increases by increasing cutter blade number, $\beta$.

3. The reduction in water hyacinth volume, $\Delta \mathrm{V} \%$, increases by increasing pump intake suction cone diameter ratio, $D_{i} / D_{s}$ and mixture volume flow rate ratio, $Q / Q_{\max }$,

4. The reduction in water hyacinth volume, $\Delta \mathrm{V} \%$, increases by decreasing the inclination angle of the centerline of the pump suction cone with respect to the vertical plane, $\theta$

\section{NOMENCLATURES}

$D_{s} \quad$ Pump suction diameter

$D_{i} \quad$ Cone inlet diameter

$\mathrm{H} \quad$ Submergence height

M Recovered mass of the Nile water hyacinth

$\mathrm{M}_{\max } \quad$ Maximum amount of the Nile water hyacinth $=2$ $\mathrm{Kg}$

Q Water-Nile water hyacinth mixture flow rate

$D_{i} / D_{s} \quad$ The ratio between cone inlet diameter and pump suction diameter

$\mathrm{H} / \mathrm{D}_{\mathrm{s}} \quad$ The ratio between submergence height and pump suction diameter

$\mathrm{Q} / \mathrm{Q}_{\max }$ The ratio between Water-Nile water hyacinth mixture flow rate and maximum water-Nile water hyacinth mixture flow rate

$\mathrm{N} / \mathrm{N}_{\max }$ The ratio between cutter speed and maximum cutter speed

$V_{1} \quad$ The volume of water hyacinth before recovers

$V_{2} \quad$ The volume of water hyacinth after recovers

$\Delta \mathrm{V} \quad$ The reduction in Nile water hyacinth volume $=\left[\left(\mathrm{V}_{1}-\mathrm{V}_{2}\right) /\right.$ $\left.V_{1}\right]$

$\beta \quad$ Cutter blade number

$\theta \quad$ Inclination angle of the pump suction cone with respect to the vertical plane

\section{REFERENCES}

Almoustapha, O., Kenfack, S. and Millogo-Rasolodimby, J., 2009 "Biogas production using water hyacinths to meet collective energy needs in a sahelian country", The Institute Veolia Environment. Field Actions Sci. Rep., Copernicus Publications Vol. 2, pp. 27-32.

Choudhary, M.P. 2002 "Applicability of Water Hyacinth for Treatment of Domestic Wastewater" ME Dissertation, MBM Engineering College, JNVU, Jodhpur.

Gunnarsson, C.C, Petersen, C.M., 2007 "Water hyacinths as a resource in agriculture and energy production: A literature review" Waste Manag. , Vol. 27, pp117-129

Khalil, M. F., Kassab, S. Z., Abdel Naby, A. A., and Azouz, A. 2009, "Parametric Performance Study of a Recovery Pumping System Handling Nile Water Hyacinth" European J. Science Research, 2009, Vol. 38, pp. 81-95.

Khalil, M. F., Kassab, S. Z., Abdel Naby, A. A., and Azouz, A. 2010a, "Performance of a Pumping System Handling Nile Water Hyacinth under Variable Operating Conditions" J. Int. Environmental Application \& Science, Vol. 5, pp. 99-112.

Khalil, M. F., Kassab, S. Z., Abdel Naby, A. A., and Azouz, A. 2010b, "Influence of Pump Impeller Type on the Performance of a Recovery Pumping System Handling Nile Water Hyacinth" European J. Science Research, Vol. 41, pp. 497-514.

Khalil, M. F., Kassab, S. Z., Abdel Naby, A. A., and Azouz, A. 2010c, "Effectiveness of a Recovery Pumping System Handling Nile Water Hyacinth" American J. Sci. Ind. Rec., Vol. 1, pp. 56-65.

Malik, A., 2007 "Environmental challenge vis a vis opportunity: the case of water hyacinth" Environ. Int., Vol. 33, pp. 122-138

Mathur, S. and Singh, P., 2004 "A Cylindrical Chopper with Crusher for Water Hyacinth Volume and Biomass Reduction" J. Aquatic Plant Manage, Vol.42, pp. 9599. 